\title{
ANALISA PENGARUH VARIASI BENTUK ABSORBER PADA ALAT DESTILASI AIR LAUT TERHADAP KENAIKAN SUHU AIR DALAM RUANG PEMANAS DAN JUMLAH PENGUAPAN AIR YANG DIHASILKAN
}

\author{
Aldi Mukaddim, Made Wirawan, Ida Bagus Alit \\ Jurusan Teknik Mesin Fakultas Teknik Universitas Mataram \\ JIn. Majapahit No.62 Mataram Nusa Tenggara Barat Kode Pos: 83125 \\ Telp. (0370) 636087; 636126; ext 128 Fax (0370) 636087
}

\begin{abstract}
Clean water is a requirements of very important human life. Indonesia is a maritime country that has many islands surrounded by ocean, had a decreased clean water problem. One of the method to be used for obtain clean water is sea water distillation process. One of the most important tools is absorber distillation. occurs heat transfer from the absorber to the sea water causing, rising sea temperatures cause sea water to evaporate. The rising temperature of the sea water increases the amount of evaporation that occurs. The more the amount of evaporation generated will increase the number of fresh water produced.

Increased seawater temperatures by increasing the temperature absorber, so it needs to be analyzed shape of the absorber which one can be produce more clean water than the others, a conclusion of the study indicated that solar distillation plat shape with a huge wave absorber produces more clean water than the others, the average amount of water that is more of $908 \mathrm{ml}$, compared with a small wave absorber plate only produce $764.4 \mathrm{ml}$ average a day and a flat plate absorber only produce $599 \mathrm{ml}$ average a day, it is not independent of heat absorption by absorber, solar distillation plat shape with a huge wave absorber absorbs more heat than the other two absorber plates, this has resulted in solar distillation shape with a huge wave absorber plate very well produce more water than the otehrs.
\end{abstract}

Keywords: shape, absorber, destilation

\section{PENDAHULUAN}

Berkembangnya isu kelangkaan bahan bakar membuat, pengembangan energi terbarukan kini banyak dilakukan oleh berbagai pihak. Hal ini dilakukan menyusul kenaikan harga minyak dunia yang menimbulkan kekhawatiran di masyarakat akan melambungnya harga bahan bakar minyak (BBM) , terutama premium. Pengembangan energi terbarukan terus dilakukan oleh kalangan perguruan tinggi, melalui karya yang diciptakan oleh para mahasiswa dan dosennya. (Inggried,2012)

Salah satu energi terbarukan yang dikembangkan saat ini adalah energi surya, energi surya merupakan salah satu energi alternatif yang potensial untuk dikelola dan dikembangkan lebih lanjut sebagai sumber cadangan energi terutama bagi negara nagara yang terletak di khatulistiwa. Peluang pemanfaatan energi surya, sebagai energi alternatif, di Indonesia semakin besar mengingat Indonesia secara geografis sebagai negara tropis dimana pancaran energi surya tercurah sepanjang tahun.

Destilasi merupakan salah satu proses pengolahan air asin menjadi air tawar yang relative murah sehingga sesuai untuk digunakan oleh masyarakat menengah ke bawah dan pada daerah yang sulit mendapatkan air bersih contohnya daerah pesisir pantai.

Menurut prediksi Badan Pusat Statistik (BPS) bahwa pada 2015 jumlah penduduk Indonesia melonjak menjadi 247,5 juta jiwa. Pertambahan penduduk tersebut berbanding lurus dengan kebutuhan air, dan diprediksi menjadi 9.391 miliar $\mathrm{m}^{3}$ atau naik 47 persen dari tahun 2000. Padahal ketersediaan air cenderung menurun setiap tahunnya, salah satu kasus didaerah padat penduduk (Pulau Jawa), ketersediaan air hanya $1.750 \mathrm{~m}^{3}$ per kapita per tahun, jauh di bawah standar kecukupan yaitu $2.000 \mathrm{~m}^{3}$ per kapita per tahun. Permasalahan ini apabila tidak ditanggulangi , dipastikan Indonesia akan mengalami kelangkaan air bersih pada 2015. Diperkirakan, ketersediaan air pada tahun tersebut hanya $1.200 \mathrm{~m}^{3}$ per kapita per tahun. (Agustiar,2007)

Oleh karena itu, diperlukan adanya alternatif metoda pengolahan air asin yang memiliki efisiensi pengolahan yang tinggi 
dan biaya yang relatif terjangkau. Dalam permasalahan ini destilasi surya merupakan salah satu solusi yang tepat untuk digunakan dan dikembangkan. (Astawa, 2008)

Destilasi surya yang digunakan selama ini umumnya menggunakan absorber dengan bentuk pelat datar yang di cat hitam sebagai penyerap matahari. pada penelitian kali ini peneliti akan menganalisa pengaruh dari 3 bentuk variasi absorber yang akan digunakan yaitu absorber pelat datar, absorber pelat bergelombang besar dan absorber pelat bergelombang kecil yang semuanya di cat hitam, Diharapkan pada analisa ini akan diketahui bentuk absorber alat destilasi surya yang efisien yang dapat menghasilkan air tawar yang paling banyak.

M. Syahri, (2011) berpendapat bahwa penggunaan absorber dengan bentuk gelombang (separuh elips melintang) menghasilkan laju penguapan yang tinggi dibandingkan dengan absorber dengan bentuk pelat datar hal ini dikarenakan luasan penyinaran efektif atau luas pelat pada absorber pelat bergelombang lebih luas dibandingkan pelat datar.

Dalam Penelitian lainnya, Sugeng Abdullah (2005) telah melakukan pengujian pada beberapa destilator surya pelat datar dengan luasan yang berbeda dan mendapatkan hasil bahwa destilator dengan luasan paling besar yang menghasilkan jumlah penguapan yang tinggi.

Beberapa hal tersebut mendasari perlunya untuk mengembangkan teknologi destilasi ini untuk mendapatkan efisiensi yang tinggi atau jumlah penguapan yang tinggi. Salah satunya dengan melakukan analisa terhadap ketiga bentuk absorber yang akan digunakan, agar dapat diketahui absorber yang paling banyak menghasilkan air tawar.

\section{LANDASAN TEORI}

\subsection{Perpindahan Panas}

Sebagai suatu gambaran mengenai tiga cara perpindahan panas dalam sebuah alat pemanas cairan surya, panas mengalir secara konduktif sepanjang pelat penyerap dan melalui dinding saluran. Kemudian panas dipindahkan ke fluida dalam saluran dengan cara konveksi, apabila sirkulasi dilakukan dengan sebuah pompa, maka disebut konveksi paksa. Pelat penyerap yang panas itu melepaskan panas ke plat penutup kaca (umumnya menutupi kolektor) dengan cara konveksi alamiah dan dengan cara radiasi.Bila dua benda atau lebih terjadi kontak termal maka akan terjadi aliran kalor dari benda yang bertemperatur lebih tinggi ke benda yang bertemperatur lebih rendah, hingga tercapainya kesetimbangan thermal. Proses perpindahan panas ini berlangsung dalam 3 mekanisme, yaitu : konduksi, konveksi dan radiasi.

\subsection{Radiasi Surya.}

Radiasi adalah perpindahan panas tanpa melalui suatu perantara, Intensitas radiasi matahari akan berkurang oleh penyerapan dan pemantulan oleh atmosfer saat sebelum mencapai permukaan bumi.

Ada tiga macam cara radiasi matahari/surya sampai ke permukaan bumi yaitu :

a. Radiasi langsung (Beam/Direct Radiation) adalah radiasi yang mencapai bumi tanpa perubahan arah atau radiasi yang diterima oleh bumi dalam arah sejajar sinar datang.

b.Radiasi hambur (Diffuse Radiation) adalah radiasi yang mengalami perubahan akibat pemantulan dan penghamburan.

c.Radiasi total (Global Radiation) adalah penjumlahan radiasi langsung dan radiasi hambur. Karena itu radiasi total pada suatu permukaan bidang miring biasanya dihitung. Besarnya energi yang dapat diperoleh dari radiasi surya adalah perkalian intensitas radiasi yang diterima dengan luasan dengan persamaan :

$Q_{\text {Pancaran }}=\sigma A T^{4}$

$A$ adalah Luasan permukaan radiasi.(m) T adalah Suhu (K)

Dimana $\quad \sigma_{\text {ialah }}$ konstanta proporsionalitas dan disebut konstanta Stefan Boltzmann dengan nilai 5,67 $\times 10^{-8}$ $\mathrm{W} / \mathrm{m}^{2} . \mathrm{K}^{4}$, perlu dicatat bahwa persamaan ini hanya berlaku untuk radiasi thermal saja.

\section{(J.P Holman 1988)}

\subsection{Konduksi.}

Panas mengalir secara konduksi dari daerah yang bertemperatur tinggi ke daerah yang bertemperatur rendah.

Besarnya kalor yang berpindah pada perpindahan kalor secara konduksi akan berbanding lurus dengan gradient temperatur pada benda tersebut.

Laju perpindahan panas konduksi dapat dinyatakan dengan Hukum Fourrier sebagai berikut :

$$
Q_{\text {konduksi }}=-k A\left(\frac{d T}{d X}\right)
$$


dimana :

$\mathrm{K}$ adalah konduktivitas $\left(\mathrm{W} / \mathrm{m}^{2} .{ }^{0} \mathrm{C}\right)$

$A$ adalah luas permukaan konduksi $\left(\mathrm{m}^{2}\right)$

$\left(\frac{d T}{d X}\right)$ adalah selisih perubahan suhu

yang terjadi terhadap jaraknya

(Sugeng A.,2005)

\subsection{Konveksi}

Konveksi adalah perpindahan panas oleh gerakan massa pada fluida dari suatu daerah ruang ke daerah lainnya. Udara yang mengalir di suatu permukaan absorber pada sebuah alat destilator, dipanasi secara konveksi yaitu konveksi alamiah. Pada umumnya laju perpindahan panas dapat dinyatakan dengan hukum pendinginan Newton sebagai berikut :

$$
Q_{\text {konveksi }}=h A_{c}\left(T_{w}-T_{f}\right)
$$

dimana :

$h$ adalah koefisien konveksi $\left(\mathrm{W} / \mathrm{m}^{2} .{ }^{0} \mathrm{C}\right)$ $\left({ }^{0} \mathrm{C}\right)$

$A_{c}$ adalah luas permukaan konveksi $\left(\mathrm{m}^{2}\right)$

$\mathrm{T}_{\mathrm{w}}$ adalah temperatur permukaan pelat

$\mathrm{T}_{\mathrm{f}}$ adalah temperatur fluida $\left({ }^{0} \mathrm{C}\right)$

(J.P Holman, 1986)

\subsection{Analisa Laju penguapan air}

Anggito dkk (2001),mengatakan bahwa untuk menghitung kesetimbangan panas dan Heat Flux radiasi pada sistem destilasi dapat digunakan rumus berikut :

$Q_{\text {in }}=Q_{\text {absorb }}+Q_{\text {losses }}$

$$
\frac{Q_{i n}}{A}=I \cdot \tau \cdot a_{p}
$$

I adalah Intensitas surya. $\left(\mathrm{W} / \mathrm{m}^{2}\right)$

$\tau$ adalah Transmivitas kaca.

$a_{p}$ adalah Absortivitas pelat penyerap.

Untuk Heat Flux konduksi pelat seng dan styrofoam pada sistem desalinasi dapat dihitung dengan menggunakan persamaan berikut ;

$$
\frac{Q_{\text {konduksi }}}{A}=\frac{k}{x} \cdot\left(T_{\text {pelat }}-T_{\text {styrofoam }}\right)
$$

Sedangkan untuk menghitung Heat Flux konveksi pelat dan air pada sistem destilasi menurut geankoplis menggunakan persamaan berikut :

$$
\begin{aligned}
& \frac{Q_{\text {plat-air }}}{A}=h .\left(T_{\text {pelat }}-T_{\text {air }}\right) \\
& \frac{Q_{\text {kaca-udara }}}{A}=h .\left(T_{\text {kaca }}-T_{\text {udara }}\right)
\end{aligned}
$$

Dan yang terakhir menurut Ketut $A$. (2011) bahwa energy berguna alat destilasi surya merupakan energy yang dibutuhkan untuk menguapkan air laut yang menjadi produk air bersih selama proses. Untuk persamaan energy berguna destilasi dapat dilihat sebagai berikut

$$
Q_{u s e}=\frac{m \times h_{f g}}{t}
$$

$m$ adalah Massa produk air bersih $(\mathrm{kg})$.

$\mathrm{h}_{f g}$ adalah Panas laten penguapan $(\mathrm{J} / \mathrm{kg})$.

$t$ adalah lama pengujian (s)

\subsection{Posisi Matahari berdasarkan deklanasi}

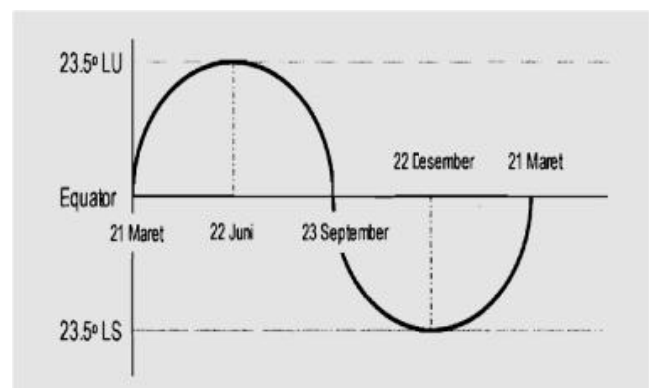

Gambar 2.1 Letak posisi matahari terhadap bumi selama setahun ditinjau dari sudut deklinasinya.

Deklinasi $(\delta)$, yaitu sudut yang dibentuk oleh matahari dengan bidang ekuatornya, ternyata berubah sebagai akibat kemiringan bumi dari $23,45^{\circ}$ (21 Juni) ke $23,45^{0}$ (21 Desember).

\subsection{Karakteristik Radiasi dari Permukaan yang Bertingkahlaku Seperti Benda Hitam \\ Nilai emisivitas dari suatu materi} sangat tergantung kepada sifat atau ciri khas dari permukaan material tersebut yang dipengaruhi oleh proses manuvacturing, perlakuan panas, serta reaksi kimia dengan lingkungan sekitarnya.

Sifat dari permukaan radiasi (emisivitas) didefinisikan sebagai perbandingan radiasi yang dihasilkan oleh permukaan terhadap radiasi yang dihasilkan 
oleh permukaan benda hitam pada temperatur yang sama. Emisivitas mempunyai nilai yang berbeda tergantung kepada panjang gelombang dan arahnya. Nilai emisivitas bervariasi dari 0 sampai dengan 1, dimana benda hitam mempunyai nilai emisivitas 1.

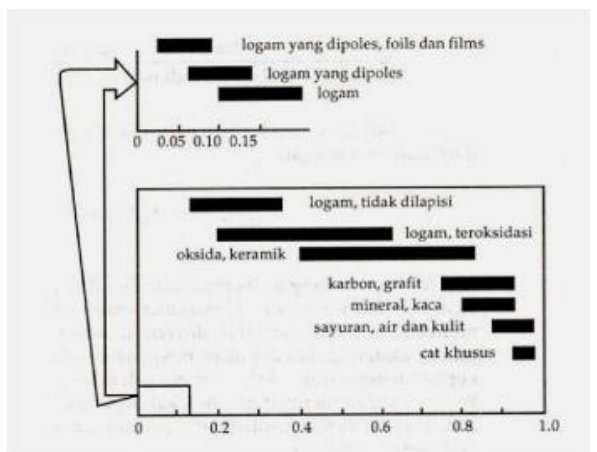

Gambar 2.2. Beberapa nilai emisivitas pada beberapa benda

\subsection{Laju aliran pada alat destilasi surya}

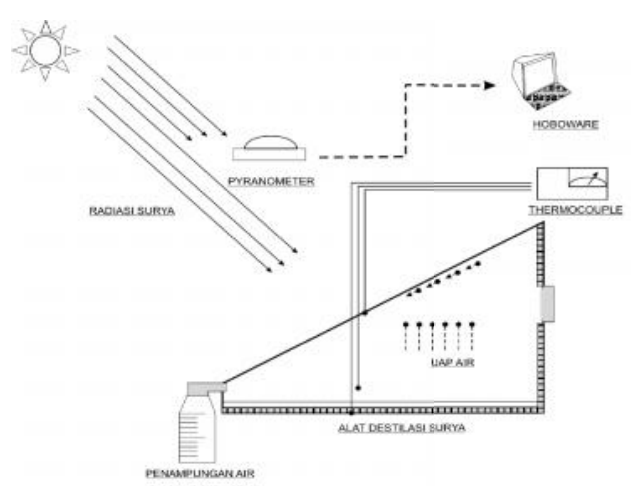

Gambar 2.3. Laju aliran uap air

Sistem operasi dalam proses destilasi meliputi peristiwa penyerapan energi panas dari sinar matahari yang menembus kaca destilator oleh absorber pelat bergelombang yang ada dalam destilator, energi panas yang diserap digunakan untuk memanaskan dan menguapkan air laut yang ada dalam alat destilator sehingga uap air dan garam akan terpisah, uap - uap air yang telah terpisah akan menempel pada permukaan kaca, dikarenakan posisi kaca miring uap uap air tersebut akan berkumpul pada dasar kaca dan keluar pada saluran outlet dan ditampung pada penampung air tawar, dan bila air laut pada alat destilator telah habis, maka kita dapat memasukan air laut ke dalam alat destilator melalui saluran inlet.

\section{METODE PENELITIAN}

\subsection{Studi Literatur dan Perancangan Alat Destilasi}

Study literatur dilakukan untuk mendapatkan data - data awal yang dapat menunjang perancangan alat destilasi, dimulai dari mencari data bahan yang akan digunakan, struktur geometrinya dan data lainnya yang menunjang penelitian. Setelah data-data terkumpul, baru dimulailah pembuatan alat destilasi yang diinginkan.

\subsection{Pembuatan Alat Destilasi}

Adapun tahap pembuatan alat destilasi adalah sebagai berikut :

1. Alat dan bahan penelitian antara lain

- Gelas ukur,

- Thermocouple,

- pyranometer,

- Jam,

- 2 buah Seng gelombang 0,20 yang di cat hitam, yang berbeda besar gelombangnya dan 1 buah seng pelat datar 0,20 yang semua di cat hitam.

- Styrofoam

- $\quad$ Air laut, sebanyak 25 liter.

- Kerangka alat destilasi,

- Cat, adapun cat yang digunakan adalah cat dengan merk polybest

2. Perencanaan alat

Adapun dimensi alat destilasi adalah sebagai berikut :

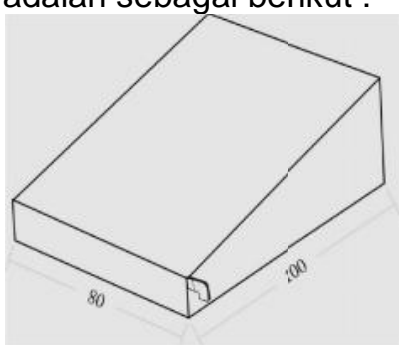

(a)

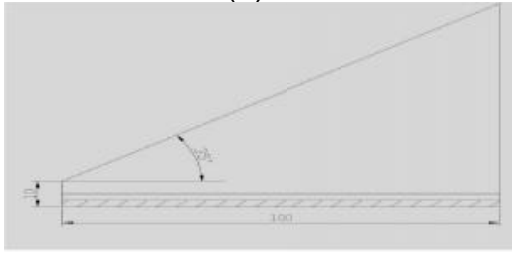

(b)

Gambar.3.1. Dimensi alat Destilasi yang digunakan (a) gambar 3 dimensi (b) gambar tampak samping 
Sudut kemiringan cover yang digunakan adalah $35^{\circ}$,dan tingginya disesuaikan agar dapat membentuk sudut $35^{\circ}$.

3. Pembuatan alat destilasi

4. Mempersiapakan alat yang akan digunakan untuk pengukuran. Peletakan thermocouple pada alat destilator surya

\subsection{Pengujian/Pengambilan data}

Pengujian/Pengambilan data dimulai pada pukul 10.00 wita sampai dengan pukul 14.00 wita dalam kondisi cuaca cerah dengan prosedur sebagai berikut :

a. Meletakan 3 buah alat destilasi surya dibawah sinar matahari secara langsung, dan memposisikannya sesuai dengan arah matahari Untuk daerah di kota Mataram dengan posisi $8^{0} 34^{\prime} \mathrm{LS}$ $116^{\circ} 11^{\prime} B T$ untuk tanggal 22 oktober 2012 hingga 27 oktober posisi matahari akan cenderung berada pada lintang selatan hingga alat destilasi surya diposisikan menghadap kea rah selatan.

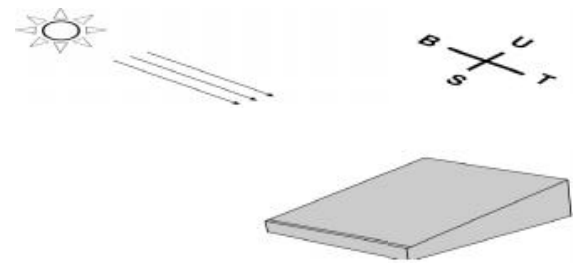

Gambar.3.2. Posisi peletakan alat destilasi surya terhadap matahari

b. Menuangkan air laut ke dalam alat destilasi surya dengan jumlah 25 liter, tidak dilakukannya penambahan air dalam jangka satu hari, untuk dapat mengetahui berapa liter air tawar yang dapat dihasilkan dalam satu hari.

c. Melakukan pengukuran awal nilai intensitas matahari, temperature lingkungan, temperatur permukaan kaca, temperatur air laut dan temperatur absorber.

d. Melakukan pengukuran bertahap selang waktu 15 menit terhadap intensitas matahari, temperature lingkungan, temperature permukaan kaca, temperature air laut dan temperature absorber, serta jumlah air tawar yang dihasilkan.

e. Melakukan pengulangan pengujian sebanyak 5 kali

\subsection{Pengolahan Data}

Setelah data didapatkan dari hasil pengujian, maka dilakukan pengolahan data untuk dapat menentukan kolektor yang lebih efisien dalam menghasilkan air tawar.

\section{HASIL DAN PEMBAHASAN}

\subsection{Analisa Data}

\subsubsection{Kemampuan Penyerapan Panas}

Untuk dapat mengetahui kemampuan penyerapan panas yang dilakukan oleh ke tiga alat destilasi dapat kita tinjau melalui panas yang diterima oleh absorber alat destilasi dan kalor berguna atau panas yang digunakan untuk menguapkan air laut menjadi uap air.

Panas yang diterima oleh ke tiga pelat absorber merupakan perpindahan panas secara radiasi dari panas matahari ke pelat absorber, untuk mengetahui seberapa besar perpindahan panas yang terjadi dapat kita hitung menggunakan rumus

$$
Q_{\text {in }}=I \cdot \tau \cdot a_{p} \cdot A
$$

Dimana transmivitas kaca $(\mathrm{T})$ bernilai 0,92 dan absortifitas pelat seng $\left(\alpha_{p}\right)$ bernilai 0,64 (Basaria,T.,2005), dan A adalah luas absorber yang tegak lurus arah panas 0,8 $\mathrm{m}^{2}$ sehingga nilai kalor radiasi datang adalah

$$
\begin{aligned}
& Q_{\text {in }}=I \cdot \tau \cdot a_{p} \cdot A \\
& Q_{\text {in }}=835,8 \cdot 0,92 \cdot 0,64 \cdot 0,8 \\
& Q_{\text {in }}=393,69 \text { watt }
\end{aligned}
$$

Data yang dipergunakan dalam perhitungan merupakan data pengukuran alat destilasi surya pada tanggal 22 oktober pukul 12.00

Sedangkan kalor berguna pada alat destilasi merupakan kalor yang digunakan untuk menguapkan air laut menjadi air tawar selama proses. Kalor tersebut dapat dihitung menggunakan rumus :

$$
Q_{u s e}=\frac{m \times h_{f g}}{t}
$$

Dimana nilai $m$ adalah massa air tawar yang dihasilkan $(\mathrm{kg}), \mathrm{h}_{\mathrm{fg}}$ adalah panas laten penguapan $(\mathrm{kJ} / \mathrm{kg})$, dan $\mathrm{t}$ adalah waktu proses pengujian.

- Massa air tawar yang dihasilkan

Untuk mencari massa air tawar yang dihasilkan dapat dihitung menggunakan rumus :

$m=\rho \times V$ 
Dimana $\rho$ adalah massa jenis air yang digunakan, $\left(\mathrm{kg} / \mathrm{m}^{3}\right)$ dan $V$ adalah volume produk air bersih yang dihasilkan $\left(\mathrm{m}^{3}\right)$.

$$
\begin{aligned}
& m=\rho \times V \\
& m=991,75 \frac{\mathrm{kg}}{\mathrm{m}^{3}} \times 50 \times 10^{-6} \mathrm{~m}^{3} \\
& m=49588 \times 10^{-6} \mathrm{~kg}
\end{aligned}
$$

- Kalor berguna

$$
\begin{aligned}
& Q_{u s e}=\frac{m \times h_{f g}}{t} \\
& Q_{\text {use }}=\frac{49588 \times 10^{-6} \mathrm{~kg} \times 2318,81 \frac{\mathrm{kJ}}{\mathrm{kg}}}{900 \text { sekon }} \\
& Q_{\text {use }}=128 \text { watt }
\end{aligned}
$$

\subsection{Pembahasan}

\subsubsection{Perbandingan antara rata-rata} $\mathbf{Q}_{\text {use }}$ ke tiga alat destilasi surya.

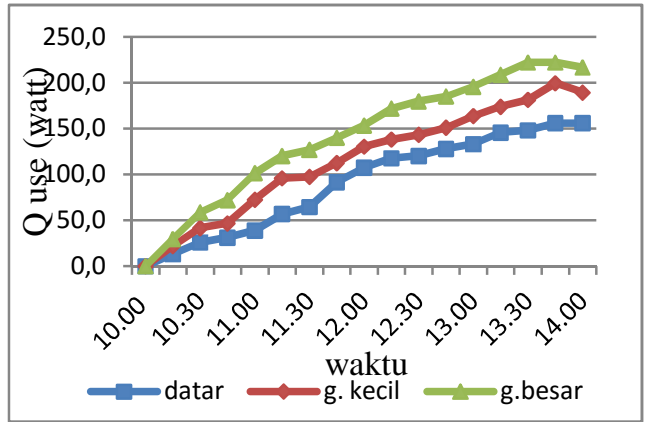

Gambar 4.1 Grafik perbandingan rata-rata $Q_{\text {use ketiga alat destilasi surya terhadap }}$ waktu.

Pada Gambar 4.1 menunjukan bahwa rata -rata panas yang digunakan untuk mengubah air laut menjadi uap $\left(\mathrm{Q}_{\text {use }}\right)$ pada pukul 10.00 wita sampai 14.00 wita pada ketiga alat destilasi surya mengalami peningkatan.

Sedangkan kalor yang diterima oleh pelat absorber ketiga alat destilasi surya $\left(Q_{\text {in }}\right)$ dapat dilihat pada grafik 4.2 (b) pada menit awal bernilai 321,38 watt perlahan meningkat hingga mencapai nilai maksimalnya 399,70 watt pada pukul 12.00 kemudian perlahan menurun hingga 346,44 watt pada pukul 14.00 . Hal ini dikarenakan nilai $Q_{\text {in }}$ dipengaruhi oleh intesitas matahari sehingga salah satu faktor yang mempengaruhi naik turunnya kalor yang diterima oleh absorber tergantung dari berapa besar intensitas mataharinya.

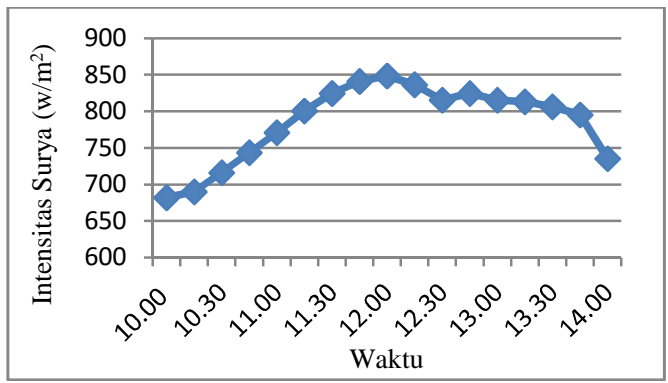

(a)

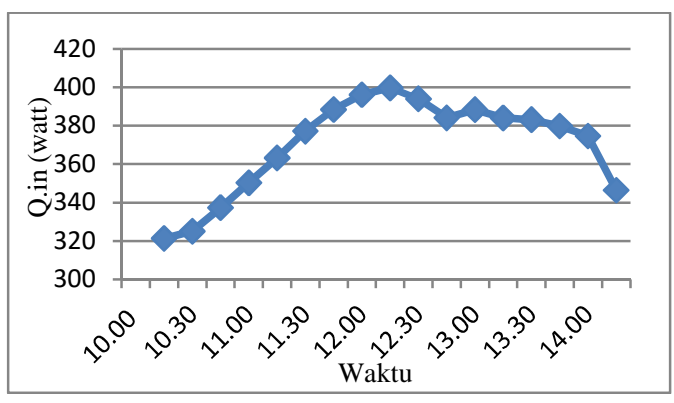

(b)

Gambar 4.2 (a) Grafik nilai rata-rata intesitas matahari yang didapatkan didapatkan selama penelitian, dan (b) Grafik nilai kalor yang diterima oleh ketiga alat destilasi surya.

Berdasarkan Gambar 4.2 (a), nilai dari rata - rata intensitas matahari yang didapatkan selama penelitian, pada awalnya cenderung meningkat dari nilai $682,3 \mathrm{w} / \mathrm{m}^{2}$ pada pukul 10.00 meningkat hingga $848,5 \mathrm{w} / \mathrm{m}^{2}$ pada pukul 12.00 dan kemudian perlahan menurun kembali hingga $735,5 \mathrm{w} / \mathrm{m}^{2}$ pada pukul 14.00 , penyebabnya dikarenakan pada pukul 12.00 jarak matahari dengan bumi lebih dekat dibandingkan dengan sebelum (pukul 10.00) dan sesudah pukul 12.00 (pukul 14.00).

\subsubsection{Perbandingan Temperatur Pelat, dan Temperatur Air pada ketiga alat destilasi dengan waktu .}

Berdasarkan dari rumus perpindahan panas (konduksi,konveksi,dan radiasi) yang berpengaruh terhadap luas benda yang tegak lurus dengan arah datangnya panas maka pada saat pukul 12.00 atau disaat matahari tepat tegak lurus di atas kepala kita,nilai perpindahan panas yang diterima akan sama besarnya untuk ketiga pelat absorber yang digunakan dikarenakan 
luasan dimensi secara tegak lurusnya sama yaitu $0,8 \mathrm{~m}^{2}$, sedangkan pada waktu yang lainnya, arah sinar matahari akan membentuk sebuah sudut yang dapat dimaksimalkan oleh pelat bergelombang sehingga penyerapan panasnya lebih baik dibandingkan dengan plat datar.

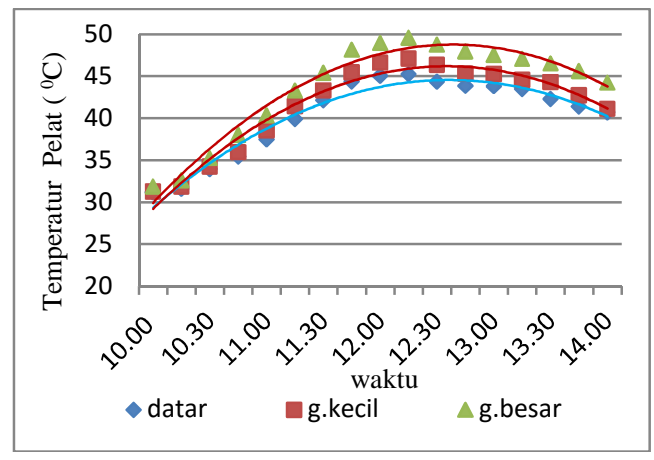

Gambar 4.3 Grafik perbandingan temperatur pelat ketiga alat destilasi surya,.

Berdasarkan Gambar 4.2 dan 4.3 dapat kita ketahui bahwa temperatur absorber meningkat sesuai dengan nilai intensitas surya yang ada dan menurun pada saat nilai intensitas surya rendah, hal ini menandakan pengaruh dari intensitas surya terhadap temperatur pelat absorber.

Dari Gambar 4.3 dapat diketahui bahwa nilai temperatur absorber pada alat destilasi surya, paling kecil dimiliki oleh pelat datar dan temperatur pelat absorber yang paling tinggi dimiliki oleh pelat gelombang besar. Hal ini disebabkan, dengan adanya bentuk gelombang radiasi sinar matahari yang mengenai pelat absorber sebagian dipantulkan ke kaca sebagian dipantulkan ke bagian gelombang sampingnya,sehingga pada absorber pelat gelombang dapat memanfaatkan panas dari sinar matahari lebih baik dibandingkan dengan pelat pelat absorber datar walaupun panas dari sinar matahari yang mereka dapatkan sama.

Pada absorber gelombang kecil memiliki temperatur absorber yang lebih rendah dibandingkan dengan temperatur gelombang besar, hal ini dikarenakan pada pelat absorber gelombang besar lebih dapat memanfaatkan sinar matahari. Absorber gelombang besar lebih banyak memantulkan sinar radiasi matahari dan lebih terpusat pada bagian sampingnya,dibandingkan pada absorber gelombang kecil,hal ini menyebabkan pelat absorber gelombang besar bertemperatur lebih besar.
Pengaruh dari temperatur absorber pelat pada ketiga alat destilasi surya adalah dapat meningkatkan temperatur air yang berada di atas permukaan pelat tersebut, sehingga temperatur pelat yang tinggi dapat meningkatkan temperatur air menjadi lebih cepat dan dapat menghasilkan air tawar lebih banyak, pengaruh dari meningkatnya temperatur air terhadap waktu dapat kita lihat dari Gambar 4.4.

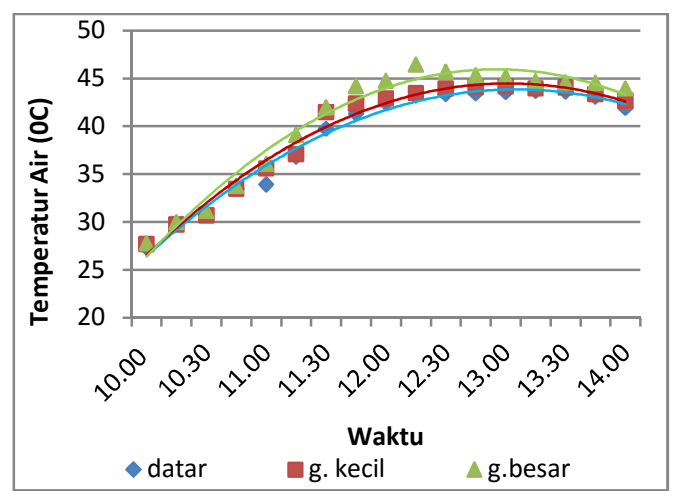

Gambar 4.4 Grafik perbandingan

temperature air ketiga alat destilasi surya.

Pada Gambar 4.4 Menunjukan perbandingan pada temperatur air pada ketiga alat destilasi surya, terhadap waktu. Dari grafik dapat dilihat pada waktu yang sama, temperatur air yang paling tinggi dimiliki oleh alat destilasi dengan absorber gelombang besar, ini menandakan temperatur air yang terdistribusi dari pelat absorber pelat gelombang lebih besar atau memiliki panas yang lebih besar dibandingkan kedua absorber lainnya yang menyebabkan temperatur air pada alat destilasi surya tersebut menjadi lebih besar dibandingkan kedua alat destilainnya.

Dari Gambar 4.4 dapat kita lihat bahwa rata - rata temperatur air pada ketiga alat destilasi surya mencapai puncaknya pada pukul 12.30 dan perlahan menurun sedikit demi sedikit, sedangkan pada pelat absorber pada ketiga alat destilasi surya mencapai puncaknya pada pukul 12.15 dan penurunan suhunya lebih banyak dibandingkan dengan temperatur air, hal ini disebabkan karena nilai konduktivitas thermal dari absorber lebih besar yaitu $112,2 \mathrm{~W} / \mathrm{m}^{2}$ dibandingkan air yaitu sebesar $0,556 \mathrm{~W} / \mathrm{m}^{2}$ mengakibatkan laju hilangnya panas pada pelat absorber lebih cepat sedangkan air lebih lambat. 


\subsubsection{Hubungan antara air yang dihasilkan ketiga alat destilasi surya dengan waktu, intensitas surya dan Temperatur lingkungan.}

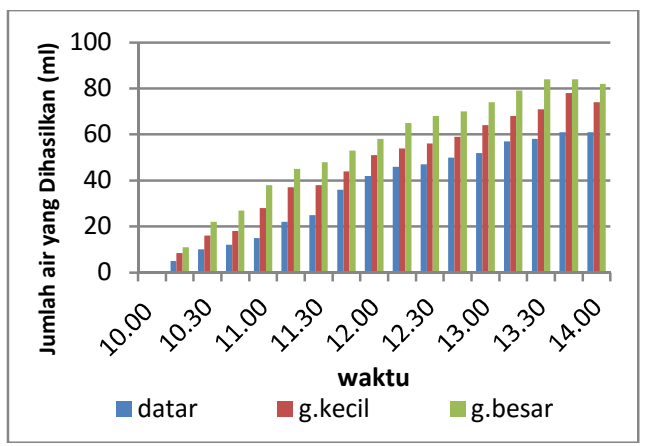

Gambar 4.5 Grafik perbandingan antara air yang dihasilkan oleh ketiga alat destilasi surya terhadap waktu.

Untuk mengetahui hubungan antara air yang dihasilkan oleh ketiga alat destilasi surya terhadap waktu, dapat dilakukan dengan membuat grafik seperti Gambar 4.5. dketahui dari grafik bahwa alat destilasi surya dengan menggunakan pelat absorber gelombang besar cenderung menghasilkan air lebih banyak dibandingkan dengan kedua alat destilasi lainnya, walaupun pada 15 menit awal jumlah air yang dihasilkan sebesar $5 \mathrm{ml}$ untuk pelat datar, $8,4 \mathrm{ml}$ untuk pelat bergelombang kecil dan $11 \mathrm{ml}$ untuk pelat bergelombang besar akan tetapi untuk setiap 15 menit selanjutnya air tawar yang dihasilkan oleh alat destilasi surya dengan pelat bergelombang besar cenderung meningkat lebih besar, diikuti oleh alat destilasi surya pelat bergelombang kecil dan yang paling sedikit dihasilkan oleh alat destilasi surya dengan pelat datar.

$$
\text { Kecenderungan meningkatnya }
$$

jumlah air yang dihasilkan oleh ketiga alat destilasi surya terhadap waktu penelitian (pukul 10.00 - 14.00) disebabkan peningkatan kalor panas yang diterima dan dijaga oleh ketiga alat destilasi yang digunakan, hal tersebut dikarenakan semakin lama waktu penelitian kecenderungan intensitas matahari semakin meningkat dan menyebabkan panas yang diterima oleh ketiga alat destilasi air laut semakin banyak,dan dikarenakan kemampuan isolasi dari ketiga alat destilasi tersebut menyimpan panas sehingga ruang didalam destilasi tetap terjaga dan meningkatkan panas sehingga jumlah air yang dihasilkan oleh ketiga alat destilasi surya semakin meningkat.

\subsubsection{Jumlah air yang dihasilkan}

Untuk mengetahui jumlah penguapan air yang dihasilkan ketiga alat destilasi surya, maka kita perlu mengasumsikan bahwa uap air yang terjadi selama pengambilan data telah terkondensasi menjadi air tawar yang tertampung. Maka kita dapat menghitungnya sebagai jumlah air tawar yang dihasilkan alat destilasi surya.

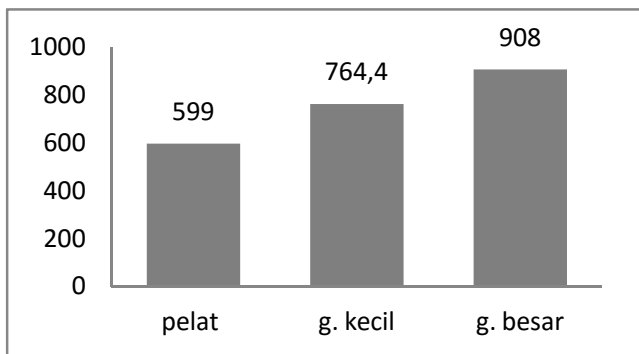

Gambar. 4.6. Grafik rata - rata jumlah air yang dihasilkan ketiga alat destilasi dalam sehari (satuan $\mathrm{ml}$ )

Dari gambar 4.6 dapat kita ketahui bahwa rata-rata jumlah air yang paling banyak dihasilkan dari ketiga alat destilasi surya berasal dari alat yang menggunakan absorber gelombang besar dengan rata rata jumlah total yang dihasilkan sehari (dalam 4 jam) yaitu $908 \mathrm{ml}$, dan jumlah yang paling sedikit dihasilkan oleh alat destilasi yang menggunakan absorber pelat datar dengan rata - rata jumlah total yang dihasilkan sehari yaitu $599 \mathrm{ml}$, dan untuk alat yang menggunakan absorber gelombang kecil menghasilkan air tawar sebanyak $764,4 \mathrm{ml}$ dalam sehari.

Ditinjau dari jumlah air yang dihasilkan maka dapat disimpulkan bahwa penggunaan absorber dengan gelombang besar lebih baik dibandingkan dengan absorber bergelombang kecil dan absorber pelat datar.

\section{KESIMPULAN}

Dari penelitian kali ini didapatkan beberapa kesimpulan, yaitu sebagai berikut:

1. Ditinjau dari jumlah air yang dihasilkan untuk ketiga alat destilasi surya, alat destilasi surya dengan absorber pelat gelombang besar menghasilkan rata rata jumlah air yang lebih banyak yaitu sebesar $908 \mathrm{ml}$, dibandingkan dengan absorber pelat bergelombang kecil yang 
hanya menghasilkan $764,4 \mathrm{ml}$ rata rata sehari dan absorber pelat datar hanya menghasilkan $599 \mathrm{ml}$ rata - rata perhari.

2. Ditinjau dari penyerapan panasnya, alat destilasi surya dengan pelat bergelombang besar lebih banyak menyerap panas dibandingkan dengan kedua pelat absorber lainnya.

\section{SARAN}

Untuk menyempurnakan hasil penelitian kedepannya, maka beberapa hal berikut perlu dipetimbangkan.

1. Perlu dipertimbangkan waktu penelitian, sebaiknya waktu penelitian dilakukan disaat matahari mendekati garis equator dengan demikian panas yang diterima oleh alat destilasi surya akan sangat maksimal, dan bila diperlukan data untuk suhu terendah dapat dilakukan penelitian disaat posisi matahari paling jauh dari garis equator.

2. Perlu dipertimbangkan waktu penelitiannya diperpanjang, agar dapat dihasilkan data yang maksimal selama satu hari penuh.

3. Perlu dipertimbangkan untuk menggunakan bentuk absorber lainnya, agar dapat diketahui pengaruhnya.

\section{DAFTAR PUSTAKA}

Agustiar, D.R., 2007, Indonesia Terancam Kekurangan Air Bersih, Tempo interaktif.com, http://www.tempointeraktif.com diunduh pada tanggal 12 Februari 2012

Anggito, dkk., 2001, Heat Transfer Pada Sistem Desalinasi Tenaga Surya dengan Pelat Penyerap Berbasis Tembaga.

Anonim., 2010, Kementerian Energi dan Sumber Daya Mineral, http://www.esdm.go.id, diunduh pada tanggal 30 Maret 2012

Anonim., $\quad$ Seng,http:///wikipedia.com (teriemahan), diunduh pada tanggal 25 Maret 2012

Anonim., SNI Baja Lapis Lembar Seng, Standar Nasional Indonesia (SNI) - 07-2053-2006, http:///www.bsn.co.id diunduh pada tanggal 12 April 2012

Astawa, K., 2008, Pengaruh Penggunaan Pipa Kondensat Sebagai Heat Recovery Pada Basyn Type
Solar Still terhadap efisiensinya, Jurnal IImiah Teknik Mesin CAKRAM vol. 2 no. $1,34-41$

Basaria,T., 2005, Menciptakan Kenyamanan Thermal dalam Bangunan, Jurnal Sistem Teknik Industri Volume 6 no. 3 juli 2005.

Brinkworth., 1976,Solar Energy For Man, ContonPress.

Inggried., 2012, Energi Baru dan Terbarukan Kalahkan Minyak, Kompas.com, http://www.kompas.com, diunduh pada tanggal 12 Februari 2012

J.P.,Holman,_1988, Heat Transfer, Mc Graw Hill Inc.

Ketut,A.,Made,S.,Putu,G.A.N., $\quad$ Analisa Performansi Destilasi Air Laut Tenaga Surya Menggunakan Penyerap Radiasi Surya Tipe Bergelombang Berbahan Dasar Beton, Jurnal Teknik Mesin Cakram vol.5 no.1 April 2011 (7-13).

Mostafa,H.S,.2010, thermophysical properties of seawater : a review of existing correlation and data.

Nova, R., 2010, Pengaruh Bentuk Cover Terhadap Produktifitas Dan Efisiensi Solar Still, Laporan Penelitian Universitas Widyagama Malang

Sugeng, A., 2005, Pemanfaatan Destilator Tenaga Surya (Solar Energy) untuk Memproduksi air tawar dari air laut .Laporan Penelitian Universitas Gadjah Mada Yogyakarta.

Syahri, M., 2011,Rancang Bangun Sistem Desalinasi energy surya menggunakan absorber bentuk separuh elip melintang ,Prosiding Seminar Nasional Teknik Kimia Kejuangan, Yogyakarta 22 Februari 2011

William,B.,John,A.D., 2006, Solar Energy and Thermal Process, university Rajiv Gandhi Proudyogiki Vishwavidyalaya,UG.

Wisnubroto, S., 2004, Meteorologi Pertanian Indonesia, Fakultas Pertanian UGM Yogyakarta. 